\title{
Simulasi Perubahan Back Rake Angle Polycrystalline Diamond Carbide Drill Bit untuk Meminimalkan Keausan Pahat
}

\author{
Oegik Soegihardjo ${ }^{1 *}$, Samuel Trinata ${ }^{2}$ \\ 1,2 Program Studi Teknik Mesin, Fakultas Teknologi Industri, Universitas Kristen Petra \\ Л. Siwalankerto 121-131, Surabaya 60236, Indonesia \\ * Penulis korespondensi; E-mail: oegik@petra.ac.id
}

\begin{abstract}
ABSTRAK
Proses pengeboran sumur minyak menggunakan mata bor untuk membuat lubang guna mengalirkan minyak mentah dari perut bumi ke permukaan tanah. Keausan pahat terjadi pada setiap proses potong maupun pengeboran yang menggunakan pahat. Drill bit adalah sebutan umum untuk mata pahat yang digunakan dalam proses pengeboran. Dua jenis mata pahat yang umum digunakan adalah roller cone dan Polycrystalline Diamond Drill atau PDC. Kasus yang terjadi adalah mata pahat PDC mengalami keausan sehingga menyebabkan unplanned bit trip. Penelitian dilakukan sebagai upaya untuk mengurangi keausan yang terjadi pada mata pahat PDC. Penelitian yang dilakukan adalah mensimulasikan perubahan back rake angle, sehingga diketahui dampak back rake angle terhadap keausan yang terjadi. Hasil penelitian dibandingkan dengan data keausan pahat yang terjadi di salah satu lokasi pengeboran minyak.
\end{abstract}

Kata kunci: Mata pahat PDC; back rake angle; keausan pahat.

\begin{abstract}
The drilling process of an oil well uses a drill bit to drill a hole to drain crude oil from the bowels of the earth to the ground. Tool wear occurs in every cutting or drilling process that uses tool bits. A drill bit is the general term for the tool blade used in the drilling process. Two types of tool bits that are commonly used are roller cone and Polycrystalline Diamond Carbide drill bit or PDC. The case being study is the wear out of the PDC drill bit, that causing unplanned bit trip. This research was conducted as an effort to reduce the wear that occurs on the PDC drill bit. The aim of the research is to simulate the changes of the back rake angle, so that the impact of the back rake angle's changes on the wear of the drill bit could be investigated. The results of the simulations were compared with the tool wear data that occurred at one of the oil drilling locations.
\end{abstract}

Keywords: PDC drill bit, back rake angle, tool wear

\section{PENDAHULUAN}

Minyak mentah adalah bahan baku dari bahan bakar minyak yang dimanfaatkan sebagai bahan bakar kendaraan dan industri. Salah satu tempat pengeboran minyak terdapat di Nordland Ridge Area. Kejadian di lokasi pengeboran di Nordland Ridge Area adalah drill bit mengalami unplanned bit trip. Unplanned bit trip disebabkan adanya keausan pada drill bit. Dampak yang ditimbulkan karena unplanned bit trip adalah kinerja yang buruk sehingga diperlukan drill bit baru, sehingga akibat pergantian drill bit tersebut maka waktu pengeboran bertambah lama yang mengakibatkan bertambahnya biaya yang dikeluarkan. Untuk meminimalkan terjadinya unplanned bit trip maka faktor yang berpengaruh pada keausan pahat adalah mengubah back rake angle mata pahat yang terdapat pada drill bit sehingga keausan yang terjadi pada drill bit berkurang.

Menurut Jadoun [1] PDC Drill bit memiliki back rake angle antara $0^{\circ}$ sampai $25^{\circ}$. Masing-masing back rake angle memiliki gaya potong yang berbedabeda. Majdi [2] menjelaskan bahwa gaya pemotongan yang terjadi pada $P D C$ drill bit merupakan gaya geser (shear force) karena PDC drill bit melakukan pemotongan tanah dengan memberikan gaya geser yang lebih besar dari kekuatan geser (shear) tanah. Namun demikian gaya geser yang besar pada mata pahat dapat mengakibatkan terjadinya deformasi. Deformasi yang berlebihan tersebut menandakan mata pahat mengalami keausan yang akan menyebabkan gross fracturing sebagaimana dinyatakan Pin [3]. 
PDC drill bit memiliki dua bagian yaitu bagian inner diameter yang posisinya berada di 2/3 bagian dari diameter drill bit dan bagian outer diameter yang berada di 1/3 bagian berikutnya dari diameter drill bit. Perhitungan tingkat keausan yang dialami mata pahat dapat menggunakan grading scale. Grading scale memiliki skala 0 sampai 8 . Pada saat grading scale sebesar 0 maka mata pahat tidak mengalami keausan dan saat grading scale sebesar 8 maka mata pahat mengalami keausan seluruhnya. Timonin [4] menyebutkan bahwa pengeboran harus dihentikan saat terdapat mata pahat yang mengalami keausan lebih dari $60 \%$ dari besar diameter drill bit hal ini dikarenakan efisiensi pengeboran menurun secara signifikan.

Bestebit [5] menjelaskan bahwa pengukuran tingkat keausan drill bit didapatkan dengan cara mengukur keausan pada masing-masing mata pahat, kemudian tingkat keausan tersebut akan diratarata. Hasil rata-rata tingkat keausan yang memiliki nilai desimal akan dibulatkan pada angka terdekat.

\section{METODE PENELITIAN}

Gambar 1 merupakan tahapan-tahapan alur penelitian. Studi literatur dilakukan untuk mempelajari kasus-kasus keausan pahat serta dampaknya, yang terjadi di berbagai lokasi pengeboran minyak. Keausan drill bit menjadi problem dalam pengeboran karena tingkat kekerasan lapisan tanah berbeda-beda. Karena keausan menjadi faktor penting yang mempengaruhi unjuk kerja pengeboran, analisis kemampuan drill bit penting untuk diketahui agar unjuk kerja proses pengeboran maksimal [Marbun dkk, 6]. Lebih lanjut Marbun dkk [6] menyatakan walaupun cara konvensional untuk mengurangi keausan drill bit bisa dilakukan, yaitu mengurangi laju penetrasi (penetration rate) pengeboran, namun cara ini akan memperpanjang waktu pengeboran.

Simulasi pengaruh back rake terhadap keausan pahat akan diverifikasi berdasarkan data keausan pahat pada pengeboran di Nordland Ridge. Masalah di lokasi pengeboran tersebut adalah drill bit mengalami keausan sehingga menyebabkan unplanned bit trip. Salah satu cara untuk mengurangi tingkat keausan pada drill bit dapat dilakukan dengan merubah back rake angle. Hal ini terjadi karena back rake angle yang berubah akan mengakibatkan perubahan cutting force, sebagaimana dinyatakan oleh Han [7].

Penelitian Jindal [8] menyebutkan jika cutting force semakin besar maka tingkat keausan pahat juga akan semakin besar dan demikian juga sebaliknya. CAD drawing dan simulasi merupakan bagian tahapan simulasi menggunakan perangkat lunak. Saat pembuatan CAD drawing dari drill bit dan lapisan tanah, beberapa parameter proses dan data property juga dimasukkan di software sebagai data input proses simulasi. Beberapa data untuk property tersebut adalah mass density, yield strength, ultimate tensile strength. Setelah data property dimasukkan, maka akan dilakukan pembuatan drill bit dengan menggunakan software Solidwork.

Tahapan simulasi dilakukan dengan menggunakan software ANSYS. Analisis untuk simulasi dengan software ANSYS ini menggunakan Transient Structural Analysis. Sebelum dilakukan simulasi maka perlu disiapkan data validasi untuk mengetahui perbedaan tingkat keausan antara hasil simulasi dengan hasil pengeboran sesungguhnya. Setelah ada kesesuaian antara hasil simulasi dengan data validasi maka dilakukan simulasi berikutnya pada drill bit dengan perubahan back rake angle mulai dari $0^{\circ}-25^{\circ}$.

Analisis merupakan tahapan untuk membahas hasil simulasi terhadap data yang digunakan untuk keperluan validasi dan pengambilan kesimpulan berdasarkan bahasan yang dilakukan. Analisis hasil simulasi dilakukan untuk mengetahui akurasi hasil simulasi terhadap data yang digunakan untuk keperluan validasi, dan menentukan back rake angle yang menghasilkan tingkat keausan rata-rata yang paling kecil.

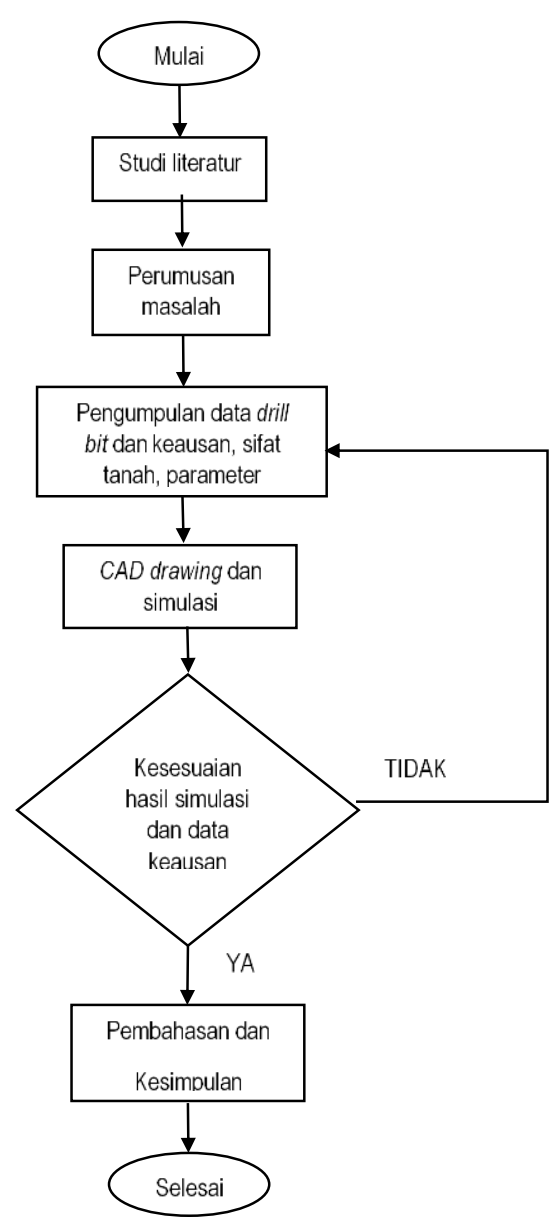

Gambar 1. Bagan alir Metodologi Penelitian. 


\section{HASIL DAN PEMBAHASAN}

Pengeboran pada sumur Sesam dilakukan dengan menggunakan polycrystalline diamond carbide (PDC) drill bit. Gambar 2 merupakan design drill bit yang digunakan dalam simulasi menggunakan perangkat lunak atau software ANSYS.

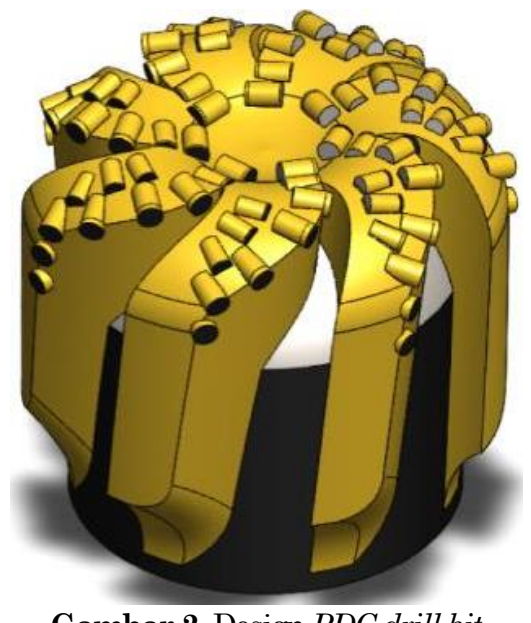

Gambar 2. Design PDC drill bit

Pengeboran pada sumur Sesam terdiri dari 3 tahap, dimana masing-masing tahap memiliki kedalaman pengeboran yang berbeda-beda. Simulasi pengeboran dilakukan pada tahap ketiga, hal ini dipilih karena perbandingan tingkat keausan ratarata dan jarak pada pengeboran tahap ketiga lebih besar dibandingkan dengan tingkat keausan ratarata terhadap pengeboran tahap lainnya. Sebelum mencari back rake angle yang memiliki tingkat keausan rata-rata yang paling kecil maka perlu dilakukan validasi. Validasi dilakukan pada 3 tahap pengeboran. Tujuan validasi adalah untuk mengetahui besar perbedaan antara tingkat keausan drill bit hasil simulasi dengan tingkat keausan drill bit pada pengeboran sesungguhnya. Tabel 1 merupakan parameter simulasi pengeboran pada masing-masing tahap

Laju pengeboran dinyatakan dalam parameter ROP (rate of penetration). Hasil simulasi yang telah dihasilkan pada masing-masing tahap perlu diratarata untuk mengetahui tingkat keausannya. Tabel 2 merupakan tingkat keausan rata-rata yang terjadi pada pengeboran masing-masing tahap.

Setelah mengetahui tingkat keausan rata-rata yang terjadi pada masing-masing tahap, maka perlu dilakukan pembulatan tingkat keausan tersebut. Pembulatan perlu dilakukan karena hasil tingkat keausan yang terdapat pada IADC grading berupa angka bulat, dan pembulatan dilakukan pada angka yang mendekati. Tabel 3 merupakan hasil pembulatan tingkat keausan rata-rata yang terjadi pada drill bit.

Tabel 2. Tingkat keausan yang terjadi pada pengeboran masing-masing tahap

\begin{tabular}{|c|c|c|c|c|c|c|}
\hline \multicolumn{7}{|c|}{ Pengeboran tahap pertama } \\
\hline \multicolumn{3}{|c|}{ inner diameter } & \multicolumn{4}{|c|}{ outer diameter } \\
\hline hat & 1 pahat 2 & pahat 3 & pahat & pahat 5 & pahat 6 & pahat 7 \\
\hline \multirow[t]{2}{*}{1} & 0 & 2 & 3 & 3 & 0 & 0 \\
\hline & rata-rata & .1 & & rata-rata & & 1,5 \\
\hline \multicolumn{7}{|c|}{ Pengeboran tahap kedua } \\
\hline \multicolumn{3}{|c|}{ inner diameter } & & \multicolumn{3}{|c|}{ outer diameter } \\
\hline ahat & 1 pahat 2 & pahat 3 & pahat & pahat $5 \mathrm{r}$ & pahat 6 & nah \\
\hline & 0 & 2 & 3 & 3 & 0 & 0 \\
\hline & rata-rata & .1 & & rata-rata & & 1,5 \\
\hline \multicolumn{7}{|c|}{ Pengeboran tahap ketiga } \\
\hline \multicolumn{4}{|c|}{ inner diameter } & \multicolumn{3}{|c|}{ outer diameter } \\
\hline \multirow{3}{*}{$\begin{array}{c}\text { ahat } \\
0\end{array}$} & pahat 2 & pahat 3 & pahat & pahat $5 \mathrm{p}$ & pahat 6 & paha \\
\hline & 0 & 1 & 3 & 4 & 0 & 0 \\
\hline & rata-rata & 0,333333 & & rata-rata & & 1,75 \\
\hline
\end{tabular}

Tabel 3. Pembulatan tingkat keausan rata-rata.

\begin{tabular}{|c|c|c|c|c|}
\hline $\begin{array}{c}\text { Tahap } \\
\text { pengeboran }\end{array}$ & Tingka & keausa & rata-rata & $\begin{array}{c}\text { Pembulatan } \\
\text { outer }\end{array}$ \\
\hline Tahap 1 & 1 & 1,5 & 1 & 2 \\
\hline Tahap 2 & 1 & 1,5 & 1 & 2 \\
\hline Tahap 3 & 0,33 & 1,75 & 0 & 2 \\
\hline
\end{tabular}

Hasil pembulatan tingkat keausan rata-rata yang ditunjukkan pada Tabel 3 akan divalidasi dengan hasil keausan pahat pengeboran sesungguhnya. Tabel 4 merupakan perbandingan antara tingkat keausan drill bit hasil pengeboran dengan hasil simulasi.

Tabel 4. Perbandingan tingkat keausan rata-rata drill bit

\begin{tabular}{cccccc}
\hline \multicolumn{6}{c}{ Hasil Pengeboran } \\
\hline \multicolumn{2}{c}{ Tahap pertama } & \multicolumn{2}{c}{ Tahap kedua } & \multicolumn{2}{c}{ Tahap ketiga } \\
\hline inner & outer & inner & outer & inner & outer \\
\hline 1 & 2 & 1 & 2 & 0 & 2 \\
\hline \multicolumn{7}{c}{ Hasil Simulasi } \\
\hline \multicolumn{2}{c}{ Tahap pertama } & Tahap kedua & Tahap ketiga \\
\hline inner & outer & inner & outer & inner & outer \\
2 & 2 & 2 & 2 & 1 & 2 \\
\hline
\end{tabular}

Hasil simulasi tingkat keausan rata-rata pada drill bit dengan tingkat keausan pahat pada pengeboran sesungguhnya tidak jauh berbeda. Perbedaan tingkat keausan drill bit hasil simulasi terjadi hanya pada inner diameter. Karena tidak ada

Tabel 1. Input ANSYS pada tiap tahap.

\begin{tabular}{ccccccccc}
\hline \multicolumn{7}{c}{ Parameter simulasi pengeboran } \\
\hline \multicolumn{2}{c}{ Tahap pertama (1046 meter) } & \multicolumn{3}{c}{ Tahap kedua (510 meter) } & \multicolumn{3}{c}{ Tahap ketiga (72 meter) } \\
\hline $\mathrm{ROP}(\mathrm{m} / \mathrm{h})$ & waktu(jam) & waktu(detik) & $\mathrm{ROP}(\mathrm{m} / \mathrm{h})$ & waktu(jam) & waktu(detik) & $\mathrm{ROP}(\mathrm{m} / \mathrm{h})$ & waktu(jam) & waktu(detik) \\
14,19 & 73,713883 & 265369,979 & 15,36 & 33,203125 & 119531,25 & 3,87 & 18,60465 & 66976,74 \\
\hline
\end{tabular}


perbedaan yang signifikan, maka hasil simulasi dapat dilakukan untuk mencari back rake angle yang dapat menurunkan tingkat keausan rata-rata. Simulasi pada pengeboran tahap ketiga dilakukan pada back rake angle $0^{\circ}-25^{\circ}$. Tabel 5 merupakan data tingkat keausan rata-rata dan besar cutting force yang didapatkan dari hasil simulasi.

Berdasarkan data pada Tabel 5 didapatkan bahwa hasil tingkat keausan rata-rata dan cutting force saat mendekati back rake angle $25^{\circ}$ semakin berkurang atau semakin kecil jika dibandingkan saat mendekati back rake angle $0^{\circ}$. Pada back rake angle $0^{\circ}$ simulasi pengeboran harus dihentikan sebelum pengeboran selesai dilakukan. Hal ini dilakukan karena pada bagian inner diameter terdapat salah satu mata pahat yang mengalami keausan melebihi $60 \%$ dari besar diameter mata pahat. Sebagaimana dinyatakan oleh Timonin [4] saat terdapat mata pahat yang mengalami keausan lebih dari $60 \%$ dari diameter mata pahat, maka pengeboran harus dihentikan.

Hasil simulasi pada Tabel 5 menunjukkan bahwa mata pahat (drill bit) di bagian atas (inner diameter) mata bor mengalami laju keausan yang lebih tinggi, sehingga lebih cepat terjadi worn out. Hal ini terjadi karena pahat di bagian atas mengalami kontak yang sangat intensif dengan lapisan tanah yang di bor.

Tabel 5. Hasil simulasi tingkat keausan yang dialami blade drill bit

\begin{tabular}{|c|c|c|c|c|c|}
\hline \multirow{2}{*}{$\begin{array}{c}\text { back rake } \\
\text { angle }\end{array}$} & \multirow{2}{*}{$\begin{array}{c}\text { inner } \\
\text { diameter }\end{array}$} & \multirow{2}{*}{$\begin{array}{c}\text { outer } \\
\text { diameter }\end{array}$} & \multicolumn{2}{|c|}{ Pembulatan } & \multirow[t]{2}{*}{$\begin{array}{r}\text { cutting } \\
\text { force }(\mathrm{N})\end{array}$} \\
\hline & & & inner & outer & \\
\hline $\begin{array}{l}\text { back rake } \\
\text { angle } 0^{\circ}\end{array}$ & worn out & 1,25 & worn out & 1 & $1,24 \mathrm{E}+10$ \\
\hline $\begin{array}{l}\text { back rake } \\
\text { angle } 5^{\circ}\end{array}$ & 1 & 2 & 1 & 2 & $1,11 \mathrm{E}+10$ \\
\hline $\begin{array}{l}\text { back rake } \\
\text { angle } 10^{\circ}\end{array}$ & 0,33 & 1,75 & 0 & 2 & $7,04 \mathrm{E}+09$ \\
\hline $\begin{array}{l}\text { back rake } \\
\text { angle } 15^{\circ}\end{array}$ & 0,33 & 1,5 & 0 & 2 & $6,93 \mathrm{E}+09$ \\
\hline $\begin{array}{l}\text { back rake } \\
\text { angle } 20^{\circ}\end{array}$ & 0,33 & 1,25 & 0 & 1 & $5,11 \mathrm{E}+09$ \\
\hline $\begin{array}{l}\text { back rake } \\
\text { angle } 25^{\circ}\end{array}$ & 0,33 & 0,5 & 0 & 1 & $4,54 \mathrm{E}+09$ \\
\hline
\end{tabular}

\section{KESIMPULAN}

Hasil simulasi ANSYS menunjukkan bahwa back rake angle mempengaruhi besar cutting force, dimana semakin besar cutting force maka tingkat keausan yang terjadi pada drill bit juga akan semakin besar.
Pada back rake angle mendekati 25o maka cutting force yang dihasilkan juga semakin kecil sehingga tingkat keausan rata-rata yang dihasilkan juga semakin kecil. Pada back rake angle mendekati $0^{\circ}$ maka cutting force yang dihasilkan juga semakin besar sehingga tingkat keausan rata-rata yang dihasilkan juga semakin besar. selain itu

Hasil simulasi juga menunjukkan bahwa tingkat keausan yang terjadi pada mata pahat bagian atas (inner diameter) lebih besar jika dibandingkan mata pahat bagian lain.

\section{DAFTAR PUSTAKA}

[1]. Jadoun, R. S., 2009, Study on Rock-drilling using PDC Bits for the Prediction of Torque and Rate of Penetration, International Journal of Manufacturing Technology and Management, 17,4 , pp 408-418.

[2]. Majdi, A., 2017, Effect of Diamond Grain Size on Wear of Polycrystalline Diamond Compact Cutter, Material Science and Engineering, 29, 3, pp 529-534.

[3]. Pin, L. T., 1992, Wear and Failure Mechanisms of Polycrystalline Diamond Compact Bits, Wear, 156, 1, pp 133-150.

[4]. Timonin, V., 2017, Causes of Wear of PDC Bits and Ways of Improving, Earth and Environmental Science, 53, 1, pp 1-7.

[5]. Bestebit, 1992, IADC Dull Grading for PDC Drill Bits. Retrieved July 20, 2018, from http://www.bestebit.com/wpcontent/uploads/2016/12/PDC-Dull-Grading.pdf

[6]. Marbun, B.T.H., Febriana, D.A., Fadholi, B.Z., and Wilantara, B., 2014, Bit Performance Evaluation in Geothermal Well Drilling, Proceedings Thirty-Ninth Workshop on Geothermal Reservoir Engineering Stanford University, Stanford, California.

[7]. Han, X., 2016, Design Front Rake Angle of PDC Bit Based on Solidwors Simulation Method, Indonesian Journal of Electrical Engineering and Computer Science, 1, 3,pp 628- 629.

[8]. Jindal, A., 2012, Analysis of Tool Wear Rate in Drilling Operation using Scanning Electron Microscope, Minerals \& Materials Characterization \& Engineering, 11,1, pp 43- 50. 